\title{
OS BENS INTANGÍVEIS E AS POLÍTICAS DE PRESERVAÇÃO DO PATRIMÔNIO CULTURAL NO BRASIL: HISTÓRIAS, NARRATIVAS E MEMÓRIAS
}

\author{
Dra. Sandra C. A. Pelegrini \\ Docente da Universidade Estadual de Maringá (UEM) - Paraná \\ Doutora em História pela Universidade de São Paulo \\ Pós-Doutora em Patrimônio Cultural pelo NEE/ UNICAMP - Campinas \\ Coordenadora do Centro de Estudos das Artes e do Patrimônio Cultural \\ (CEAPAC-UEM) \\ Pesquisadora do NEE/UNICAMP \\ Consultora do Programa de Iberoamericano de Ciencia y Tecnología para el \\ desarrollo - CYTED (Madri-Espanha)
}

Quando assistimos ao filme "Narradores de Javé", de sobressalto nos deparamos com um enredo singular que nos propõe uma reflexão crítica sobre as construções discursivas que envolvem as visões lineares de interpretação da história, além de nos permitir debater os conceitos de memória, oralidade, bens culturais e os sentidos atribuídos às políticas preservacionistas, inclusive aos critérios utilizados para se definir o que deve ou não ser preservado - questões diretamente relacionadas ao tema ora abordado.

As breves considerações que teceremos sobre essa obra do cinema nacional se devem à perspicácia da diretora, do roteirista, dos atores e demais membros da equipe que interagiram com os moradores de Gameleira da Lapa, onde essa produção foi realizada. O grupo captou de maneira incomum as filigranas da "alma" do nordestino e ao final das gravações incentivou os gamelenses a se mobilizaram em torno da organização de um projeto de reciclagem de lixo ${ }^{1}$ - aspecto que envolve outro olhar sobre as relações do homem com o meio.

Ora, quando tratamos dos bens culturais imateriais estamos lidando não apenas com saberes, celebrações ou rituais, mas também com as formas do homem se conectar ao lugar onde vive no tempo presente,

\footnotetext{
1 Em 2001, durante as filmagens, os dois mil moradores foram incentivados pelos atores e produtores a recolher e separar o lixo amontoado nas ruas, calçadas e quintais a cerca de onze anos. Eles passaram a exigir das autoridades providências para a coleta seletiva e reciclagem desse lixo. Cf. Relatos e imagens disponíveis no site: http://www.narradoresdejave.com.br . Acesso em dez. /2006.
} 
pretérito e futuro. Logo, nossas referências a "Narradores de Javé" se justificam porque a sua trama tangencia mazelas, desde longa data, enfrentadas por historiadores, antropólogos e outros pesquisadores que atuam no campo do inventariamento de bens patrimoniais tangíveis e intangíveis.

Essa produção cinematográfica, cujo gênero é definido como uma comédia, não raro, é tomada pelo público como mero entretenimento. Todavia, quando nos detemos na análise dos elementos compositivos do enredo, da fotografia, da linguagem cênica e da sensibilidade expressa nos diálogos detectamos a profundidade do tema abordado e as múltiplas leituras que nos permite efetuar. Particularmente, nos interessa apontar a visibilidade que oferece para os sentidos de pertença que a comunidade da fictícia Javé atribui ao povoado, suas expressões culturais e mitos de origem.

O longa-metragem lançado em 2004, sob a direção de Eliane Caffé, vem a público num momento muito profícuo, qual seja um ano após a Unesco ter proclamado a "Convenção do Patrimônio Imaterial". Em 2003, os debates sobre o patrimônio cultural intangível ganharam repercussão entre os especialistas e também na mídia.

Aliás, a questão do apontamento dos bens imateriais vinha sendo alvo de ponderações oficiais no Brasil desde 1998, quando foi criado o Grupo de Trabalho Patrimônio Imaterial (GTPI), a partir das disposições da Constituição de 1988. Observamos no que tange ao patrimônio cultural que os órgãos públicos levaram quase uma década para acionar instrumentos jurídicos capazes de atender as demandas concernentes a Carta Magna do Brasil. A sua distinção como meio de "expressão" e "modos de criar, fazer e viver" se tornou objeto do Decreto no. 3551, apenas no ano 2000. A partir de então, assistiríamos a paulatina implementação dos Livros de Registro de Bens Culturais de Natureza Imaterial.

Exposto isto, torna-se interessante retomar a abordagem do drama vivenciado pelos moradores de Javé, quando este estava às vésperas de ser coberto pelas águas do reservatório necessário para a construção de uma hidrelétrica - tida como signo do progresso na região. A temática abordada não é excepcional, outras manifestações artísticas como músicas e filmes se inspiraram em situações similares, como é o caso das usinas de Sobradinho 
(Bahia) ou de Itaipú (Paraná). Todavia, o que chama a atenção são as formas utilizadas por Eliane Caffé e Luis Alberto de Abreu para conduzir o roteiro e a narrativa cinematográfica ${ }^{2}$.

Segundo o enredo, na tentativa de evitar que o lugarejo desaparecesse, a comunidade "javélica" - para usar os termos recorrentes nos diálogos - inicialmente se une em torno de um projeto comum: driblar as imposições da modernidade que ameaçavam o seu cotidiano. Para tanto, opta pela estratégia de transformar o local num núcleo histórico a ser reconhecido como patrimônio, pois um deles já ouvira falar da existência de uma lei que "proibia" a destruição dos povoados elevados a essa categoria.

Tal tática foi sugerida por Zaqueu (interpretado por Nelson Xavier), personagem que narra o "causo" no seu novo estabelecimento comercial instalado às margens da represa que encobriu Javé. À época que antecedeu a inundação, ele era o comerciante que estabelecia os elos de ligação entre Javé e o ponto mais próximo de abastecimento. Sua atividade lhe conferia o contato com o "mundo" exterior e o acesso à informação.

Zaqueu iria orquestrar a mobilização da comunidade e propor que o único adulto alfabetizado assumisse o encargo de "recolher depoimentos" capazes de fundamentar o "registro cientifico" da história local. A transcrição das memórias dos moradores constituiria o documento basilar para salvaguardar o lugar e impedir o seu desaparecimento. Ao longo desse processo e em meio a situações hilárias, os indivíduos começam a esboçar seus vínculos afetivos com o lugar, bem como os seus valores culturais e religiosos.

O personagem Antônio Biá, representado pelo ator José Dumont, é impelido a redigir a história de Javé, embora tivesse sido rechaçado por escrever inúmeras cartas relevando "acontecimentos" que promoveram a maledicência e a discórdia entre os cidadãos javelenses. Esse "mal feito" fora um ardiloso recurso utilizado por ele para aumentar o volume de cartas em circulação e evitar que a Agência de Correios fechasse - o que lhe garantira o emprego como carteiro. Daí a insistência de todos no sentido de

2 E. Caffé revela que as histórias de pessoas que viviam no interior de Minas Gerais e da Bahia foram ouvidas por toda a equipe. $\mathrm{O}$ contato com esses depoimentos possibilitou a compreensão daquele universo e foi decisiva na construção do enredo e dos diálogos. Cf. GERRA, R. Entrevistas. Exclusivo: Eliane Caffé. Cineclick. Disponível em site: www.cineclick.com.br/entrevistas. Acesso em out./2006. 
que ele se comprometesse a escrever uma história "científica", não inventada como outrora o fizera.

Diante das circunstâncias, Biá assume a tarefa que lhe atribuíram e com sagacidade procura ouvir as narrativas da população residente, entretanto, tende a "floreá-las" com vistas a ampliar a carga poética da história e sua densidade dramática e/ou cômica. Após muitos percalços, o personagem depara-se com um entrave que comprometeria seu o ofício de "pseudo-historiador": chegam ao seu conhecimento cinco versões sobre o mito fundador "javélico". As múltiplas memórias e os vestígios encontrados, tomados como documentos imprescindíveis ao que poderia constituir um "inventário" dos bens materiais e imateriais do povoado, acabam por inviabilizar a confecção do "Livro da Salvação de Javé".

Eis a chave da trama: situações tragicômicas apresentam variáveis que se alternam de acordo com os entrevistados e dificultam a síntese dos "acontecimentos históricos". "Indalécio" e "Indaleô", por exemplo, são identificados como os fundadores do lugarejo. $\mathrm{O}(\mathrm{s})$ personagem(s) histórico ora personifica um fidalgo que teria contestado as imposições da Coroa portuguesa, ora representa minorias étnicas como os negros quilombolas e outros excluídos da "história oficial" como os próprios sertanejos. Do ponto de vista de uma das mulheres ouvidas, a personagem nomeada "Maria Dina" teria salvado a todos da morte e cantado as fronteiras de Javé. Além disso, entre uma bebedeira e outra, Biá pressente que o "registro científico" da história local não seria suficiente para deter os rumos do "progresso" e evitar a inundação.

A despeito da comicidade e das artimanhas dos principais personagens que representam o "povo" nordestino, nos depoimentos surgem imagens míticas, lendas, cantos e formas de pensar a história que colocam em xeque os "velhos" paradigmas da disciplina. Os vestígios do passado não são reconhecidos apenas mediante documentos textuais (praticamente inexistentes). Eles fazem aflorar embates sobre o que seria "digno" de ser preservado como "memória histórica" local.

A demarcação das fronteiras de Javé constitui outro exemplo significativo dos valores que regiam as relações entre aquelas pessoas. A delimitação das terras, comum a todas as versões, teria sido realizada por meio de um canto. Não havia um documento escrito. A tradição oral é que legitimava a posse da terra, bem como a salvaguarda deste "espaço" como "patrimônio histórico".

Em síntese, o enredo do filme problematiza os métodos da escrita da história e da oralidade, aponta pistas sobre os embates entre a "história 
oficial" e as outras histórias narradas por personagens que normalmente são privados de expor e preservar suas reminiscências.

A análise de "Narradores de Javé" não se esgota nos aspectos ora salientados. No entanto, do ponto de vista dessa reflexão, torna-se salutar observar como essa produção fílmica foi capaz de realizar uma avaliação crítica acerca da construção histórica do passado e da preservação dos bens culturais considerados representativos das "identidades", cujos sentidos e significados foram atribuídos a uma comunidade imaginária.

Ao trazer à tona a percepção das contínuas disputas pelas memórias entre os sujeitos ou segmentos da sociedade, a obra evidencia o sentido de pertença que vincula os personagens ao meio onde vivem. As referências ao mito de Indalêo surgem vigoras na narrativa cantada em dialeto africano pelo membro mais antigo do grupo. O bravo quilombola teria conduzido seu "povo" ao paraíso terrestre onde havia fartura e a integração lúdica com a água e a floresta, A oralidade é, pois, ratificada como prática milenar, capaz de transmitir às gerações futuras as experiências vividas, tal como faziam os antigos sacerdotes ou curandeiros.

Essa produção não é a única a se ocupar da criatividade daqueles que não desejam assistir inertes à aniquilação de seus valores socioculturais ou de seus lugares de origem. Mas sua relevância se destaca pelo modo como o enredo é conduzido: a "comunidade javélica" nega-se a admitir a real possibilidade de assistir o naufrágio de seus referenciais e luta por suas tradições. Em outros termos, talvez o maior legado deixado por esse filme para aqueles que se ocupam da temática do patrimônio esteja centrada na percepção de que os próprios cidadãos têm de si mesmos e que só há sentido na preservação daquilo que eles coletivamente reconhecem como valores a serem transmitidas e tratadas como herança cultural.

Por outro lado, não podemos negligenciar que a postura de alguns personagens evidencia que as culturas se transformam através dos tempos. Esse aspecto pode ser apreendido na medida em que as falas de Biá e das crianças mostram-se antenadas às "novidades" e "modismos", que de alguma forma chegam até eles. Não ao acaso, Biá faz referências às "tartarugas ninjas" e às figuras de desenhos animados americanos, altamente consumidos nos cinemas e difundidos nos programas infantis apresentados na televisão brasileira: A astúcia como tendem a absorver essas informações e digeri-las de acordo com seus interesses constitui alvo de inquietação entre os especialistas.

O desfecho do filme também não dissimula uma preocupação latente entre os estudiosos do patrimônio. Nas dramáticas cenas da 
inundação de Javé efetuadas por meio de tomadas intercaladas em planos abertos e fechados, observamos o destaque aos personagens que se negavam a deixar seus mortos, pertences e lares. Evidencia-se a intenção de salientar a consciência da perda e a luta silenciosa da "comunidade javélica" determinada a defender o seu direito de cultuar as suas memórias e os seus "lugares sagrados", onde estavam enterrados os seus antepassados. Essas imagens introduzem conceitos singulares à problemática da salvaguarda dos bens imateriais. A percepção dos laços dessa população com a terra onde criaram seus filhos e edificaram suas famílias, não se limita ao problema socioeconômico. As redes de sociabilidade e os elos afetivos entre as pessoas (amigos, vizinhos e familiares) e entre eles e o meio, ecoam nos monólogos, nos diálogos e transbordam nas lágrimas dos personagens representados por atores ou coadjuvantes residentes na locação, Gameleira da Lapa.

Outro aspecto que devemos salientar diz respeito à concepção de patrimônio imaterial que embasa as políticas públicas preservacionistas.

Quando o reservatório vai se formando e encobrindo o campanário da igreja, resignados, os moradores se esforçam para resgatar o sino. O mesmo sino carregado por uma espécie de carro de boi (recorrente nas narrativas sobre a chegada dos fundadores) é tomado como relíquia a ser preservada. Trata-se de um artefato do passado e de um marco do recomeço da vida noutro lugar.

O sino constitui um elemento representativo para a "comunidade javélica". A sua sonoridade marcava o horário das missas, sinalizava a chegada de forasteiros, o anúncio de nascimentos e mortes, momentos de alegria ou tristeza. $\mathrm{O}$ hábito de tocar o sino não se restringia às funções rituais, o instrumento era utilizado como meio de difusão de informações importantes no dia-a-dia do povoado ${ }^{3}$.

3 É sabido que esse instrumento sonoro de origem oriental se transformou num signo da cristandade e que funcionava como marcador do tempo. Nos séculos VI e VII, a sonoridade das badaladas soadas nos campanários das igrejas ou nas torres dos mosteiros passaram a regular não apenas a vida dos homens da Igreja, mas também da sociedade em geral (Cf. LE GOFF, J. A Civilização do Ocidente Medieval. Lisboa: Estampa, 1984. v.II, p. 345). Estes instrumentos sonoros, incorporados ao cotidiano dos cristãos, aportaram na América Portuguesa juntamente com a implantação da Igreja. "D. Pedro Sardinha, primeiro bispo do Brasil, assumiu sua diocese de Salvador" (1552) e trouxe consigo "ornamentos, peças de prata e outras alfaias do serviço da igreja e sinos". Cf. Montanheiro, Fábio César. Quem toca o sino não acompanha procissão: toques de sino e ambiente festivo em Ouro Preto. In: Anais do I Encontro Nacional da História das religiões e religiosidades. Maringá: Anpuh, 2007, p. 1-2. 
"Narradores de Javé" nos faz pensar criticamente a construção do discurso histórico materializado em bens culturais. Mais do que isso, nos evidencia a existência de distintos referenciais simultaneamente tangíveis e intangíveis presentes em memórias individuais e coletivas, expressivos do ponto de vista dos sentidos a eles atribuídos. Aliás, essa produção nos leva a indagar porque o reconhecimento mais amplo da cultura popular tornou imperiosa a distinção entre os bens patrimoniais e a criação da categoria "intangível" para nomear as tipologias que não se enquadravam na "definição convencional" circunscrita aos núcleos urbanos, edifícios, monumentos, artefatos, etc. Também não nos parece muito explicativa a utilização dessa categoria para classificar bens que são simultaneamente materiais e imateriais, como lugares, festas, espetáculos e alimentos.

Não podemos esquecer que a Organização das Nações Unidas para Educação, a Ciência e a Cultura/Unesco (e órgãos afins) privilegiou a preservação da cultura material desde que passou a se ocupar desse assunto em meados do século XX, após o fim da II Guerra Mundial. Entretanto, tornou-se necessário que alguns países reivindicassem o reconhecimento de tradições que não se identificavam com os valores culturais ocidentais para que autoridades políticas e especialistas internacionais encontrassem efetivas soluções para a proteção e valorização da tão decantada pluralidade cultural da humanidade 4 . A expressão "bens imateriais" está vinculada à uma acepção "moderna" da Antropologia, para qual a cultura se fundamenta nas "relações sociais ou nas relações simbólicas, mas não especificamente nos objetos materiais e nas técnicas" 5

Nessa linha de argumentação, ainda há que se indagar: é possível preservar os bens intangíveis sem salvaguardar a materialidade impregnada nas celebrações, saberes de ofício, modos de fazer beberagens, lugares tidos como sagrados ou pontos de encontro e sociabilidades? Por certo que não, mas o essencial é percebermos que a proteção de tais bens pressupõe o trânsito entre essas duas categorias: o "tangível" e o "intangível", e ainda, implica reunirmos condições necessárias para a transmissão dos conhecimentos de uma geração para a outra.

Como bem o lembra José Reginaldo Santos Gonçalves:

${ }^{4}$ Cf. PELEGRINI, S. C. A. e FUNARI, P. P. O que é patrimônio cultural imaterial. São Paulo: Brasiliense, 2008.

5 Gonçalves, J. R. S. Antropologia dos objetos: coleções, museus e patrimônios. Rio de Janeiro: MinC. IPHAN - DEMU, 2007, p. 218. 
O material e o imaterial aparecem de modo indistinto nos limites dessa categoria. A noção de patrimônio cultural (...), enquanto categoria do entendimento humano, na verdade rematerializa a noção de "cultura" que, no século XX, em suas formulações antropológicas, foi desmaterializada em favor de noções mais abstratas, tais como estrutura, estrutura social, sistema simbólico, etc. ${ }^{6}$

Talvez essa ampliação do conceito de cultura explique por que as Cartas Patrimoniais da Unesco e do ICOMOS, nas décadas finais do século XX, passaram a recomendar a indispensabilidade da catalogação de manifestações típicas da população dispersa em várias regiões do planeta7. Contudo, como podemos depreender certa morosidade na oficialização da "Convenção do Patrimônio Imaterial” (2003)?

No Brasil, as publicações de M. Andrade e C. Cascudo, nas décadas de 1920 e 1930, já explicitavam preocupações com o levantamento e a definição das manifestações da cultura popular ${ }^{8}$. Os esforços do Grupo de Trabalho Patrimônio Imaterial (GTPI), instituído em 1998 pelo Ministério da Cultura, somaram-se às atividades desenvolvidas pelo Centro Nacional de Referência Cultural (incorporado ao IPHAN em 1973) e pela Fundação Pró-Memória (extinta em 1990). Entre os desígnios do GTPI destacavam-se a formulação de estratégias para a proteção dos bens culturais intangíveis e a promoção de discussões para fundamentar a minuta do decreto presidencial que criou o Registro de bens de natureza imaterial, como instrumento de acautelamento e instituiu o "Programa Nacional de Identificação e Referenciamento de Bens Culturais de Natureza Imaterial”.

Os artigos 215 e 216 da Constituição de 1988 ofereciam garantias ao "pleno exercício dos direitos culturais" e ao "acesso às fontes da cultura nacional", além de admitir a contribuição dos indígenas e negros na formação da "nação" brasileira. Após a implantação do Decreto no. 3551/2000, a salvaguarda dos bens imateriais passou a ser efetuada oficialmente em quatro livros: dos Saberes; das Formas de Expressão; das Celebrações e dos Lugares. Até 2008 foram reconhecidos nacionalmente os seguintes bens:

1. Ofício das Paneleiras de Goiabeiras (dez./2002);

2. Arte Kusiwa dos Índios Wajãpi (dez./2002);

${ }^{6}$ Idem, p. 218.

Cabe-nos lembrar que na primeira década do século XXI, as maiores demandas de reconhecimento do patrimônio imaterial são encaminhadas por países da América Latina e do Caribe, da África, dos Estados Árabes, Ásia e do Pacífico. Cf. PELEGRINI, S. C. A. e FUNARI, P.P. Op. cit, p.57.

8 Embora não partilhassem dos mesmos matizes teóricos, ambos estavam empenhados na compreensão da realidade brasileira mediante estudos da cultura não-erudita. 
3. Samba de Roda no Recôncavo Baiano (out./2004);

4. Modo de fazer de Viola-de-cocho (jan./2005);

5. Ofício das Baianas de Acarajé (jan./2005);

6. Círio de Nossa Senhora de Nazaré (out./2005);

7. Jongo no Sudeste (dez./2005);

8. Cachoeira de Iauaretê - Lugar sagrado dos povos indígenas dos Rios Uaupés e Papuri (out./2006);

9. Feira de Caruaru (dez./2006);

10. Frevo (dez/2006);

11. Tambor de Crioula do Maranhão (jun/2007);

12. Samba do Rio de Janeiro (out./2007);

13. Modo artesanal de fazer queijo "Minas" (2008);

14. Capoeira (jul./2008);

15. O modo de fazer Renda Irlandesa produzida em Divina Pastora (Nov./2008).

A sociedade brasileira e seus respectivos especialistas parecem admitir o inevitável: a riqueza da diversidade da nossa cultura. As antigas teorias raciais depreciativas e as preocupações com a "inautenticidade" da cultura brasileira resultante do que era considerado "um largo trabalho de imitação das idéias e costumes estrangeiros", comuns entre intelectuais no século XIX, cederia lugar em meados do século XX para a "construção do mito da democracia racial". O Estado Novo de Getúlio Vargas se esforçaria para "estabelecer a síntese da nacionalidade brasileira" 9 .

Assim, inferimos que, segundo a concepção estado-novista, cabia constatar o que era "intrínseco" ao homem brasileiro, ou seja, a sua "natural" desigualdade sociocultural. Sob este prisma, o Estado Nacional devia minimizá-la reforçando os traços culturais positivos de um "povo" concebido como uma "raça de mestiços", dotada de traços morais, políticos e sociais, de modo a não abalar os pilares da "construção da nação". Tal façanha se faria por meio de símbolos e bens patrimoniais considerados representativos da história do país.

Neste contexto, adquire dimensão incomensurável a denominada Lei de Tombamento (Lei 25/1937) que se ocupa da proteção dos

9 Gontigo, Rebeca. Identidade nacional e ensino de história: a diversidade como patrimônio sociocultural. In: Abreu, Marta e Soihet (orgs.). Ensino de História: conceitos, temáticas e metodologia. Rio de Janeiro: Casa da Palavra, 2003, p.56-57. 
monumentos, obras de arte, conjuntos escultóricos e núcleos históricos. A metáfora do caldeirão de culturas, há muito acalentado para expressar a convivência harmônica entre grupos formadores da nação brasileira, não dissimula os embates pela preservação de memórias étnicas. Seria coincidência a intensa demanda de inventários de bens imateriais articulados às práticas afro-brasileiras e indígenas nessa primeira metade do século XXI? Parece-nos que a implementação da Lei 3551/2000 constitui um indicativo irrefutável de que não há acaso algum, mas a confluência de reivindicações sociais e interesses políticos.

Sem a pretensão de esgotarmos um tema tão complexo, apresentamos aqui algumas questões que do nosso ponto de vista merecem ser apreendidas com acuidade pelos estudiosos do patrimônio cultural tangível ou intangível. Por certo, as alusões às inquietudes afloradas nas posturas dos personagens de "Narradores de Javé" aguçou nossa sensibilidade e nos motivou a encerrar essa exposição com reflexões nunca acabadas. Mas que são sempre acrescidas quando direcionamos nosso olhar aos relatos sobre as trajetórias dos maiores interessados na preservação de seus bens patrimoniais, quais sejam os homens e mulheres que se reconhecem entre si, partilham identidades e exercitam práticas culturais coletivas.

\section{Bibliografia}

CORRÊA, Alexandre Fernandes. Mudanças de Paradigma preservacionista clássico: Reflexões sobre patrimônio cultural e memória étnica. Disponível em site:

http://www.antropologia.com.br/arti/colab/a2-acorrea.pdf. Acesso em julho/2006.

GICO, Vânia V. Câmara Cascudo e Mário de Andrade: uma sedução epistolar . Revista do Patrimônio Histórico e Artística Nacional, São Paulo, n. 30, pp.111 - 127, 2002.

Gonçalves, J. R. S. Antropologia dos objetos: coleções, museus e patrimônios. Rio de Janeiro: MinC. IPHAN - DEMU, 2007.

GontiJo, Rebeca. Identidade nacional e ensino de história: a diversidade como patrimônio sociocultural. In: Abreu, Marta e Soihet (orgs.) Ensino de História: conceitos, temáticas e metodologia. Rio de Janeiro: Casa da Palavra, 2003, pp.55-78.

GERRA, Roberto. Entrevistas. Exclusivo: Eliane Caffé. Cineclick. Disponível em site: www.cineclick.com.br/entrevistas. Acesso em out./2006.

KERSTEN, M. S. A. Os rituais do Tombamento e a escrita da História: Bens Tombados no Paraná entre 1938 - 1990. Curitiba: Editora da UFPR, 2000.

Kanashiro, Marta. Narradores de Javé, um filme sobre memória, História e exclusão. In: Comciencia. Resenha disponível em site: http://www.comciencia.br/resenhas/memoria/narradores.htm. Acesso em dez./2005.

LE GOFF, Jacques. A Civilização do Ocidente Medieval. Lisboa: Estampa, 1984. v.II. 
Montanheiro, Fábio César. Quem toca o sino não acompanha procissão: toques de sino e ambiente festivo em Ouro Preto. In: Anais do I Encontro Nacional da História das religiões e religiosidades. Maringá: Anpuh, 2007 , pp. 1-10.

CARDOSO, Heloísa H. C. Narradores de Javé: história, imagens e percepções. Fênix - Revista de História e Estudos Culturais v.. 5 ano 5 n. 2 - abril/maio/junho/2008, pp.1-11.

PELEGRINI, S. C. A. O patrimônio cultural no discurso e na lei: trajetórias do debate sobre a preservação no Brasil. Patrimônio e Memória - Revista Eletrônica, v. 2, n. 2, p. 1-24, Assis - São Paulo: UNESP - FCLAs - CEDAP, 2006;

PELEGRINI, Sandra C. A. A salvaguarda e a sustentabilidade do patrimônio imaterial brasileiro: impasses e jurisprudências. FUNARI, Pedro Paulo A.; PELEGRINI, Sandra C. A.; Rambelli, Gilson. Patrimônio Cultural e Ambiental: questões legais e conceituais. São Paulo: Annablume/FAPESP, 2008 (prelo).

PELEGRINI, Sandra C. A. A gestão do patrimônio imaterial brasileiro na contemporaneidade. História [online]. 2008, vol.27, n.2, pp. 145-173.

PELEGRINI, S. C. A. e FUNARI, P. P. O que é patrimônio cultural imaterial. São Paulo: Brasiliense, 2008.

Relatos sobre as filmagens de Narradores de Javé. Disponíveis no site: http://www.narradoresdejave.com.br.

Rubino, Silvana. A memória de Mário. Revista do Patrimônio Histórico e Artística Nacional, São Paulo, n. 30, pp.138 - 154, 2002.

UNESCO. Convention for the Safeguarding of the Intangible Cultural Heritage (2003). Disponível em site: http://www.Unesco.org . Acesso em jan./2005. 